\title{
By trial and error: project creation problems of the Code of Basic Labor Laws of the USSR in 1925
}

\author{
A. B. Ivanov ${ }^{1}$
}

${ }^{1}$ P. G. Demidov Yaroslavl State University, 14 Sovetskaya str., Yaroslavl 150003, Russian Federation

DOI: $10.18255 / 1996-5648-2021-3-378-387$

Research article

Full text in Russian

The article is devoted to the problems of codification of the labor legislation of the USSR in the 1920s. The empirical basics for it was the provisions of Soviet normative legal acts, materials of the practice of legal systematization, including information from unpublished (archival) sources, information from reference and scientific literature of the specified period. The work shows the main trends in the legal regulation of labor and relation closely related to them, characterizes the system of sources of labor law, touches upon the causes for its codification at the all-union level. The process of developing the draft Code of Basic Labor Laws of the USSR, which was supposed to become the first branch codified act of union significance is considered. The grounds, conditions and reasons for this codification are identified, its organizational and technical-legal aspects are investigated, and the subject composition is shown. The reasons are revealed due to which the work on the creation of an all-union labor code was not completed (lack of a clear conceptual and legal basis for codification, instability of social relations regulated by labor law, etc. The influence of the codification on the subsequent development of the Soviet labor legislation is shown.

Keywords: Codification; system of labor legislation; the Code of Basic Labor Laws of the USSR; codes of labor laws of the union republics

\section{INFORMATION ABOUT AUTHORS}

\author{
Ivanov, Artyom B. | E-mail: a.ivanov1@uniyar.ac.ru \\ Cand. Sc. (Jurisprudence), Associate Professor
}




\title{
Путем проб и ошибок: проблемы разработки проекта Кодекса основных законов о труде СССР 1925 г.
}

\author{
А. Б. Иванов ${ }^{1}$
}

${ }^{1}$ Ярославский государственный университет им. П. Г. Демидова, ул. Советская, 14, Ярославль, 150003, Российская Федерация

DOI: $10.18255 / 1996-5648-2021-3-378-387$

УДК 340.158

Научная статья

Полный текст на русском языке

Статья посвящается проблемам кодификации трудового законодательства СССР 1920-х годов. Эмпирической базой для нее послужили положения советских нормативных правовых актов, материалы практики юридической систематизации, в том числе данные из неопубликованных (архивных) источников, информация из справочной и научной литературы указанного периода. В работе показываются основные тенденции в правовом регулировании трудовых и тесно связанных с ними отношений, характеризуется система источников трудового права, затрагиваются предпосылки его кодификации на общесоюзном уровне. Рассматривается процесс разработки проекта Кодекса основных законов о труде СССР, который должен был стать первым отраслевым кодифицированным актом союзного значения. Выявляются основания, условия и поводы для данной кодификации, исследуются организационные и технико-юридические аспекты, показывается ее субъектный состав. Раскрываются причины, вследствие которых работа по созданию общесоюзного трудового кодекса не была завершена (отсутствие четкой концептуальной и юридической основы кодификации, нестабильность общественных отношений, регулируемых трудовым правом и др.). Показывается влияние кодификации на последующее развитие советского законодательства о труде.

Ключевые слова: кодификация; система трудового законодательства; Кодекс основных законов о труде СССР; кодексы законов о труде союзных республик

\section{ИНФОРМАЦИЯ ОБ АВТОРАХ}

\author{
Иванов, Артем Борисович \\ E-mail: a.ivanov1@uniyar.ac.ru \\ Кандидат юридических наук, доцент
}

(с) Иванов А. Б., 2021

Статья открытого доступа под лицензией CC BY (https://creativecommons.org/licenses/by/4.0/) 
Любой кодифицированный акт, являясь результатом как правовой систематизации, так и законотворчества, в процессе создания проходит определенные стадии, начиная от формулирования и обоснования концепции кодификации и заканчивая утверждением законопроекта компетентным органом с последующим вступлением в юридическую силу. Вместе с тем, как свидетельствует практика, далеко не всегда кодификация бывает успешной и приводит к появлению в системе законодательства нового значимого акта. В истории есть немало примеров незавершенных кодификаций, когда работы по созданию кодекса, даже весьма основательные, неожиданно прекращались по инициативе законодателя, а порой и без прямого выражения его воли. При этом правовая реформа могла останавливаться не только на ранних этапах, например во время разработки проекта акта кодификации, обсуждения его концептуальной основы, структуры и содержания (деятельность Уложенной комиссии при Екатерине II в 1767-1768 гг., подготовка Гражданского и Уголовного кодексов СССР в середине прошлого века). Печальная судьба не утверждения могла ждать даже полностью подготовленный законопроект, прошедший основную часть согласований и находившийся «на столе» у законодателя (Гражданские уложения Российской империи начала XIX и XXвв.). Известны также успешные, но чрезмерно долгие кодификации, которые, несмотря на наличие социальной потребности в правовой определенности и политической воли к усовершенствованию законодательства, не были оперативно осуществлены и служили предметом для критики со стороны специалистов и общественности (советская конституционная реформа второй половины ХХ в., подготовка КЗоТ РСФСР 1971 г. и действующего Трудового кодекса РФ 2001 г.) [1, с. 74-77]. Предложения по кодификации отдельных областей законодательства, порой весьма спорные, высказываются и в настоящее время [2].

В этой связи важно исследовать в общетеоретическом, историческом и отраслевом аспектах причины, препятствовавшие кодификации, выявлять и анализировать объективные и субъективные фракторы, замедлявшие данный процесс или не позволявшие его завершить. Изучение указанных вопросов позволит повысить качество кодификации в современных условиях. Здесь важно подчеркнуть, что перечисленные трудности кодификации в большей или меньшей степени могут быть характерны и для иной правотворческой и правосистематизирующей деятельности. Однако, в силу высокого статуса актов кодификации, их особого места в системе законодательства, важной роли в механизме правового регулирования, проблемам разработки данных актов должно уделяться первоо- 
чередное внимание. В рамках настоящей работы будет рассмотрена одна из малоизученных незавершенных кодификаций советского периода.

Определение и разграничение законотворческих полномочий органов власти различного уровня относилось к числу важных и непростых задач, которые требовалось решить в процессе создания Союзного государства. Юридической основой для такого определения и разграничения стали в итоге Договор об образовании СССР 1922 г. и Конституция СССР 1924 г. В соответствии с данными конституционными актами трудовое законодательство относилось к совместному союзно-республиканскому ведению $[3$, c. 129]. $К$ ведению Союза в лице его верховных органов акты относили «установление основных законов о труде» (п. «п» ст. 1 Договора, п. «р» ст. 1 Конституции). Смысл этой формулировки был не вполне ясен даже самому законодателю. С одной стороны, она интерпретировалась как форма союзного акта, с другой - как указание на полномочия в области законотворчества $[4$, с. $73 ; 5$, с. 14$]$. Так или иначе отсутствие четко очерченных контуров союзной кодификации не стало препятствием для практической работы в этой области.

Важно подчеркнуть, что, начиная с первых дней существования СССР, ни у практических работников, ни у представителей юридической науки не было сомнений в актуальности кодификации законодательства о труде на союзном уровне. Ключевые же ее проблемы заключались в нормативном наполнении кодекса союзного значения, в соотношении положений данного акта с нормами уже действовавших кодексов союзных республик (КЗоТ РСФСР 1922 г. и др.), в разграничении общесоюзной и республиканской компетенции в области регулирования трудовых отношений [4, с. 72]. Прийти к общему знаменателю по указанным вопросам законодателю и доктрине в 1920-е гг. так и не удалось, что стало камнем преткновения при подготовке кодекса о труде СССР.

Комплексный анализ источников говорит о том, что в 1920-е гг. сложилось три концептуальных подхода к кодификации союзного трудового законодательства.

Первый подход предусматривал детальную регламентацию трудовых отношений союзным законодательством, прежде всего трудовым кодексом СССР, который должен был заменить действовавший КЗоТ РСФСР и аналогичные акты других союзных республик (сверхкодекс). Второй подxод предполагал принятие на союзном уровне рамочного акта кодификации, определявшего лишь общие направления правового регулирования в сфере труда и предоставлявшего широкий простор для законотворчества союзным республикам (кодекс-декларация). Третий подход рассматривал кодекс СССР как акт, который, наряду с закреплением основных 
принципов трудового законодательства, должен был подробно нормировать значительную часть трудовых отношений, при этом и республиканским актам кодисрикации отводилась важная роль в решении отдельных вопросов, связанных с историческими, национальными, социально-экономическими и иными особенностями союзных республик (сбалансированный кодекс).

Первоначально законодатель ориентировался на первый подход. В целом в союзном государстве фактически сразу наметилась тенденция к регулированию труда рабочих и служащих в централизованном порядке посредством издания нормативных актов общесоюзного значения. После образования СССР было немало сторонников точки зрения, согласно которой принятый еще до учреждения Союза КЗоТ РСФСР является не чем иным, как актом общесоюзного значения. Юридическим обоснованием этой позиции служило постановление ВЦИК от 9 ноября 1922 г. «О введении в действие Кодекса Законов о Труде РСФСР», в котором указывалось, что КЗоТ распространяется на территории РСФСР и всех союзных и автономных республик и областей [6]. Данное постановление было утверждено при участии представителей других советских республик, что расширяло пространственную сферу действия российского кодекса. Кроме того, общесоюзный статус КЗоТ РСФСР подтверждался декретом ЦИК СССР от 13 июля 1923 г. «О декретах и постановлениях ВЦИК и его Президиума», в соответствии с которым все акты этих органов, которые, в силу договорных отношений между РСФСР и союзными республиками и в силу полномочий, данных ЦИК СССР Президиуму ВЦИК в декабре 1922 г., получили распространение на территории РСФСР, союзных и договорных республик, сохраняли силу как обязательные к действию на всей территории СССР [7]. У сторонников приведенной позиции не было единства лишь по вопросу о том, требуется ли принимать специальный закон об утверждении КЗоТ РСФСР в качестве Кодекса Основных Законов о Труде СССР или можно ограничиться ссылками на вышеуказанные акты. Между тем практика реализации норм КЗоТ РСФСР 1922 г., выявившая отдельные недостатки кодекса, а также изменения, происходившие в срере труда, побудили законодателя к принятию решения о подготовке нового кодифицированного акта на основе российского кодекса.

В связи с союзной кодификацией трудового законодательства весьма активно обсуждался вопрос о судьбе республиканских КЗоТ. Первое время считалось, что с принятием кодекса СССР необходимость в актах союзных республик отпадет, так как практически все вопросы будут регулироваться на общесоюзном уровне. «Совершенно недопустимо, - писала руководитель юридического отела народного комиссариата труда 
Е. Н. Данилова, - чтобы промышленный пролетариат был поставлен в различные правовые условия в отдельных частях Союза... это создало бы впечатление известной «конкуренции» между советскими республиками... Материалов для республиканских кодексов не остается, да и самое название это... имеет важное значение и нельзя запутывать рабочего, заставляя его задумываться над вопросами, чем отличается Союзный Кодекс от республиканского» [8, с. 32,41$]$.

Между тем не во всех республиках российский КЗоТ рассматривался как общесоюзный кодекс. Если в Белоруссии он долгое время (до 1929 г.) действовал под наименованием «КЗоТ РСФСР», то на Украине он сразу стал восприниматься как акт именно этой республики. Так, при утверждении КЗоТ в 1922 г. Украинский ЦИК внес в него изменения «формального конституционно характера», заменив все ссылки на органы РСФСР ссылками на соответствующие органы Украины [9, с. 12]. В целом практика по этому вопросу долгое время различалась - даже в 1950-е годы КЗоТ РСФСР действовал в 7 союзных республиках из 16 (например, в Казахской, Карело-Финской, Киргизской, Латвийской, Литовской ССР), у остальных республик были собственные кодексы [10, с. 3].

Однако уже в 1920-е гг. отдельные союзные республики решениями своих законодательных органов стали вносить изменения в КЗоТ, что фрактически перечеркивало общесоюзные «перспективы» этого закона ${ }^{1}$. «Республиканские Кодексы законов о труде, - констатировал современник кодификации, известный ученый-трудовик И. С. Войтинский, - будучи едиными в своей основе (Кодекс РСФСР 1922 г.), с течением времени значительно разошлись между собой в подробностях своего текста» [5, с. 14]. При этом у республик были различные подходы к внесению изменений и дополнений в свои кодексы. Так, если в Закавказской Федерации (ЗСФСР) основная часть принимавшихся постановлений отличалась от актов, изданных в РСФСР и СССР, только редакционно, то в УССР в этих случаях российские и союзные акты подвергались значительной переработке, что выражалось в исключении отдельных статей, введении новых статей, изменении содержания статей и т. д. Также в республиканских кодексах имели место расхождения по вопросам, которые требовали единообразной регламентации. Так, если в п. «а» ст. 34 украинского КЗоТ закреплялась норма, ограничивавшая срок трудового договора с определенным периодом действия тремя годами, то по Кодексу РСФСР предус-

${ }^{1}$ Профильные ведомства в лице народных комиссариатов труда СССР и РСФСР одно время пытались бороться с «законодательным сепаратизмом» союзных республик, опротестовывая их решения в вышестоящих инстанциях. Однако в связи с изменением политической конъюнктуры такая практика в итоге сошла на нет ( см.: Наркомтруда СССР и взаимоотношения с союзными республиками // Вопросы труда. 1923. № 2. С. 7-10.). 
матривалось заключение срочного договора на срок не свыше одного года. Положение п. «ж» ст. 47 белорусского КЗоТ предоставляло работодателю право уволить работника при непосещении последним работы вследствие временной утраты трудоспособности в течение четырех месяцев со дня ее утраты. В кодексах других союзных республик в этом случае закреплялся более низкий уровень правовых гарантий в виде двухмесячного срока. Очевидно, что определенность в республиканскую законотворческую практику должен был внести общесоюзный акт кодификации.

Таким образом, в ходе кодификации под влиянием законотворческой практики отдельных союзных республик и в связи с продолжавшимся поиском оптимальных фрорм взаимоотношений между Союзом ССР и его субъектами первый подход, базировавшийся на идее сверхцентрализации трудового законодательства, уступил место противоположному, второму, подходу, предусматривавшему децентрализацию правового регулирования в сорере труда.

Данный подход в итоге лег в основу первоначальной редакции проекта Кодекса Основных Законов о Труде CCCP (КОЗоT) [11]. Проект Кодекса был подготовлен в подкомиссии по вопросам трудового законодательства, учрежденной весной 1924 года, под руководством заместителя народного комиссара юстиции РСФСР Н. В. Крыленко. Подкомиссия являлась одним из подразделений Конституционной комиссии, которая была создана решением Президиума ЦИК СССР по поручению сессии ЦИК "для подготовки ряда законов, включая основные законы о труде». Составители проекта союзного КОЗоТ руководствовались тем, что Кодексы законов о труде, действовавшие на территории союзных республик, представляют законодательство этих республик, а не общесоюзное законодательство. В связи с этим только принципиальные положения Кодекса могли быть восприняты в основных законах о труде Союза ССР. Основная же часть вопросов, по мнению членов подкомиссии, должна была регламентироваться кодексами и другими актами союзных республик [8, с. 34-35, 36].

Однако подход, на котором базировался законопроект «подкомиссии Крыленко», недолго занимал приоритетное положение. Сам проект в скором времени подвергся критике, а его составители были обвинены в «узко-республиканском шовинизме» и в «законодательном сепаратизме» [8, с. 36]. Наиболее резко против второго подхода и проекта выступал Народный комиссариат труда СССР. Специалистами этого ведомства был подготовлен другой, более сбалансированный, проект союзного КОЗоТ, в основе которого лежал третий подход к кодификации [12]. По убеждению НКТ, на союзном уровне следовало закрепить основные принципы 
и направления правового регулирования труда, установить обязательный минимум трудовых прав и гарантий. Вместе с тем и союзным республикам требовалось предоставить широкие полномочия в области трудового законодательства [13, с. 25-26].

В целом работа над указанными проектами КОЗоТ СССР проходила в 1924-1925 гг. В это время проекты несколько раз редактировались с учетом поступавших замечаний и предложений, прошли утверждение в ряде инстанций (например, проект Наркомата труда летом 1925 г. был утвержден Президиумом ВЦСПС). Но в итоге ни один из проектов таки и не был внесен на рассмотрение законодательного органа (ЦИК СССР), а сами работы по кодификации были приостановлены.

В последующие годы законодатель не отказывался от идеи создания общесоюзного трудового кодекса. Так, в 1927 г. IV Съезд Советов СCCP указал Правительству на необходимость «в кратчайший срок издать Основной Закон о Труде». В 1930 г. СНК СССР поручил общесоюзному Наркомату труда по согласованию с ВЦСПС в полугодовой срок разработать акт в фрорме «Кодекса Законов о Труде СССР» [5, с. 14]. Однако задача принятия общесоюзного трудового кодекса в указанные годы уже не относилась к числу первоочередных, поэтому сама кодификация носила вялотекущий характер и не приносила практических результатов [3, с. 129-130]. Теоретические и практические проблемы союзной кодификации также продолжали достаточно активно обсуждаться на страницах научных изданий, однако определенности в понимании ее перспектив и стратегии по-прежнему не сложилось.

Таким образом, в середине 1920-х гг. трудовой кодекс общесоюзного значения, несмотря на значительные усилия и ресурсы, затраченные на его подготовку, не был утвержден законодателем. Одним из основных факторов, препятствовавших созданию этого акта, было «быстрое развитие трудового законодательства» [5, с. 14], отсутствие в нем требуемой для кодификации стабильности. Как отмечал один из участников кодифрикации - народный комиссар труда СССР В. В. Шмидт - «каждый раз мы ставились перед политической необходимостью регулировать условия труда в новых условиях, не имея возможности и времени тщательно продумать и проверить наши законы... В итоге получалось не систематическое законодательство о труде.., а законодательство от случая к случаю, недостаточно продуманное, недостаточно взвешенное и нагроможденное бесчисленными пояснениями и разъяснениями» [13, с. 23]. Важно также отметить, что перспективы трудового законодательства 1920 -х гг. в целом являлись весьма туманными вследствие временного характера проводившейся тогда политики (нэп) и содержания проходив- 
ших на высшем партийном и государственном уровнях дискуссий о путях построения в стране социализма. Наконец, ни на доктринальном уровне, ни на практике в указанные годы не было еще четкого понимания относительно общих подходов к построению системы законодательства в СССР, к содержанию актов союзного и республиканского значения, их соотношению друг с другом.

Вместе с тем опыт, полученный в процессе подготовки Кодекса Основных Законов о Труде СССР, оказал положительное влияние на последующее развитие кодификации. Не отказываясь в принципе от создания общесоюзного отраслевого кодекса, законодатель взял на вооружение другую тактику, успешно используя прежние наработки при кодификации отдельных институтов трудового права, что технически было проще осуществить в условиях правовой нестабильности (например, в 1928 г. ЦИК и СНК СССР были утверждены Правила о примирительно-третейском и судебном рассмотрении трудовых конфликтов, а в 1929 г. - постановление «Об имущественной ответственности рабочих и служащих за ущерб, причиненный ими нанимателям»). Позднее эта практика получила одобрение и обоснование на теоретическом уровне в качестве метода кодификации законодательства переходного периода и нормативной основы для будущего отраслевого кодекса [14, с. 47-48]. Кроме того, отдельные подходы к построению и содержанию проекта КОЗоТ СССР 1925 г., были восприняты законодателем при подготовке Основ законодательства Союза ССР и союзных республик о труде 1970 г.

\section{Ссылки}

1. Иванов А. Б. О некоторых проблемах подготовки Трудового кодекса Российской Федерации 2001 года // Вестник ЯрГУ им. П. Г. Демидова. Серия «Гуманитарные науки». 2015. № 4. С. 74-77.

2. В Госдуме предложили создать новый кодекс для сельских жителей. URL: // https://www.gazeta.ru/social/news/2021/03/15/n_15739580.shtml (дата обращения: 16.03.2021).

3. Памятники российского права: в 35 т. Т. 26: Кодексы законов о труде РСФСР: учебно-научное пособие / под ред. Р. Л. Хачатурова, А. М. Лушникова. М.: Юрлитинформ, 2016. 528 с.

4. Горшенин К. П. Кодификация законодательства о труде. Теоретические вопросы. М.: Юрид. лит., 1967. 224 с.

5. Войтинский И. Трудовой кодекс социалистической реконструкции // Советское трудовое право на современном этапе: сб. статей / под ред. А. Белова. Л.: Лениздат, 1931. С. 13-24. 
6. Постановление ВЦИК от 9 ноября 1922 г. «О введении в действие Кодекса Законов о Труде РСФСР» // СУ РСФСР 1922. № 70, ст. 903.

7. Декрет ЦИК СССР от 13 июля 1923 г. «О декретах и постановлениях ВЦИК и его Президиума» // СУ РСФСР 1923. № 82, ст. 796.

8. Данилова Е. Н. Пределы общесоюзного законодательства о труде // Вопросы труда. 1924. № 10. С. 32-42.

9. Данилова Е. Н. К проекту Кодекса основных законов о труде СCCP // Cоветское право. 1925. № 3 (15). С. 11-21.

10. Законодательство о труде: Комментарий к законодательству о труде СССР и Кодексу Законов о Труде РСФСР / Н. Г. Александров [и др.] М.: Юрид. лит., 1953. 467 с.

11. Проект Кодекса Основных Законов о Труде СССР (текст подготовлен подкомиссией Крыленко) // ГАРФ. Ф. Р-5515. Оп. 26. Д. 6. Л. 80-143.

12. Проект Кодекса Основных Законов о Труде СССР (текст подготовлен Народным комиссариатом труда) // ГАРФ. Ф. Р-5515. Оп. 1. Д. 10. Л. 15-87.

13. Шмидт В. Советское трудовое законодательство и очередные задачи нашей трудовой политики // Вопросы труда. 1925. № 7-8. С. 21-32.

14. Маврин С. П., Хохлов Е. Б. О кодификации трудового законодательства России // Государство и право. 1996. № 6. С. 42-48. 